\title{
Properties of Experimental Resins Based on Synthesized Propoxylated bis-GMA with Different Propionaldehyde Ratios
}

\author{
Aline Bassi Denis ${ }^{\mathrm{a}}$, Ana Maria Guzzi Plepis ${ }^{\mathrm{a}}$, Virginia da Conceição Amaro Martins ${ }^{\mathrm{a}}$, \\ Jose Carlos Pereira ${ }^{\mathrm{b}}$, Renato Cilli, Anuradha Prakki* \\ a São Carlos Chemistry Institute, University of São Paulo - USP, CEP 13566-590, São Carlos, SP, Brazil \\ ${ }^{\mathrm{b}}$ Department of Operative Dentistry, Endodontics and Dental Materials, Bauru Dental School, \\ University of São Paulo - USP, CEP 17012-901, Bauru, SP, Brazil \\ 'Department of Dental Materials and Operative Dentistry, Faculty of Dentistry, \\ University of Fortaleza - UNIFOR, Fortaleza, Ceara, Brazil \\ ${ }^{\mathrm{d}}$ Restorative Department, Faculty of Dentistry, University of Toronto, M5G 1G6, Toronto, ON, Canada
}

Received: March 18, 2011; Revised: February 8, 2012

\begin{abstract}
The effect of different propionaldehyde ratios on the properties of bis-GMA-based comonomers and copolymers diluted with propoxylated bis-GMA $\left(\mathrm{CH}_{3}\right.$ bis-GMA) was evaluated. Five experimental comonomers were prepared combining bis-GMA with $\mathrm{CH}_{3}$ bis-GMA and propionaldehyde at $0,2,8$, $16,24 \mathrm{~mol} \%$. Light polymerization was effected with the use of $0.2 \mathrm{wt}$. (\%) each of camphorquinone and $N, N$-dimethyl- $p$-toluidine. Resin degrees of conversion $(\% \mathrm{DC})$ were evaluated by FT-IR spectrophotometry and $\mathrm{T}_{g}$ by Differential Scanning Calorimeter. Complex viscosity $(\eta *)$, the effect of temperature on $\eta^{*}$, and Microhardness $(H)$ for dry and wet samples were also determined. Data were analyzed by Student's t-test, one-way ANOVA and Tukey-Kramer test $(\alpha=0.05)$. The group with $24 \mathrm{~mol} \%$ additive had a significant increase in $\% \mathrm{DC}$ and $H$, and the lowest comonomer $\mathrm{T}_{g}$ and $\eta *$. No remarkable variation was noted in copolymers $\mathrm{T}_{g} \mathrm{~s}$. All resins presented Newtonian behavior of viscosity, which linearly decreased with increased temperature. The $\eta *$ decreased sigmoidally as the additive ratio increased.
\end{abstract}

Keywords: aldehyde, bis-GMA analog, microhardness, rheology

\section{Introduction}

It has been reported that the incorporation of propionaldehyde as an additive to bis-GMA/TEGDMA (bisphenol glycidyl dimethacrylate/triethyleneglycol dimethacrylate) and UDMA/HEMA (urethane dimethacrylate/hydroxyethyl methacrylate) resins significantly improved their degree of conversion ${ }^{1,2}$, mechanical properties ${ }^{3}$ and in vitro wear resistance ${ }^{4}$. The extent of conversion continuously increased as the propanal content increased from 0 to $40 \mathrm{~mol} \%^{1}$. Properties such as flexural strength, diametral tensile strength, modulus of elasticity, and wear resistance improved up to an additive content of 24 to $32 \mathrm{~mol} \%$, above which the properties did not present significant changes ${ }^{3,4}$. The possibility should, however, be considered that in excess this rather volatile and relatively toxic component may leach and evaporate from the resin affecting its biocompatibility.

In Dentistry, dilution of bis-GMA with the more hydrophilic TEGDMA is known to cause clinical adverse effects, mainly because of the increase in water sorption and polymerization shrinkage ${ }^{5,6}$. To overcome these unwanted effects studies have been directed toward developing low viscosity, hydroxyl free, more hydrophobic bis-GMA analogs such as the propoxylated bis-GMA (2,2-bis(4-(2methacryloxyprop-1-oxy)phenyl)propane), as a replacement for TEGDMA in bis-GMA mixtures ${ }^{7,8}$. The properties of

*e-mail: anuradha.prakki@dentistry.utoronto.ca
bis-GMA copolymers and composites containing $\mathrm{CH}_{3}$ bisGMA (Figure 1) have been evaluated. Due to TEGDMA being a more flexible monomer, with a higher degree of conversion, the Young's modulus and flexural strength values of bis-GMA/TEGDMA systems were higher?.

To improve its mechanical properties, propionaldehyde has been incorporated into the bis-GMA/ $\mathrm{CH}_{3}$ bis-GMA system. The ratios of $24 \mathrm{~mol}$ and $32 \mathrm{~mol} \%$ were used because they were shown to promote the highest increases in the properties of methacrylates ${ }^{3,4}$. In this latter system, a significant increase was also noted in the degree of conversion ${ }^{10}$ and properties such as wear, strength, modulus of elasticity and hardness ${ }^{11,12}$. Considering the lack of studies with regard to incorporation of lower ratios of aldehyde into the mentioned developmental resin, the objective of this study was to evaluate the physical, rheological, and mechanical properties of bis-GMA diluted with $\mathrm{CH}_{3}$ bisGMA containing $0,2,8,16$ and 24 mol\% propionaldehyde.

\section{Materials and Methods}

\subsection{Materials}

Bis-GMA, the photosensitizer camphorquinone $(\mathrm{CQ}$, Kerr Corp., CA 92867-5422, USA), reducing agent $\mathrm{N}, \mathrm{N}$ dimethyl- $p$-toluidine (DMPT, Alfa Aesar, NH 03087- 


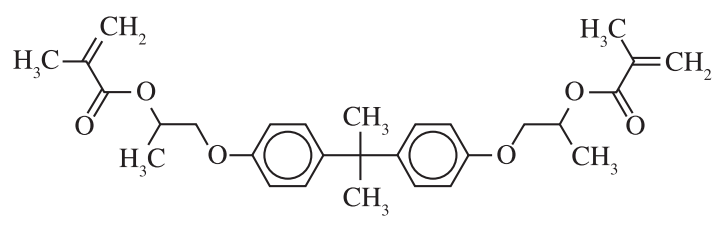

$\mathrm{CH}_{3}$ Bis - GMA

Figure 1. Molecular Structure of $\mathrm{CH}_{3}$ bis-GMA.

9977, USA), and propionaldehyde (Acros Organics, NJ 07410, USA) were all used as received. The bis-GMA analog, $\mathrm{CH}_{3}$ bis-GMA was synthesized, purified and stored according to reported methods ${ }^{7}$. Synthesized monomer was characterized by ${ }^{1} \mathrm{H}$ NMR and ${ }^{13} \mathrm{C}$ NMR, providing spectra that were consistent with the expected product (Figures $2 \mathrm{a}$ and $b$ ).

\subsection{Formulation of comonomers}

Five experimental resin formulations were prepared comprising 5 groups. For the control group bis-GMA/ $\mathrm{CH}_{3}$ bis-GMA (without additive - G0) the comonomer ratio (mol\%) was 75/25. For the other groups (G2, G8, G16 and G24) containing bis-GMA/ $\mathrm{CH}_{3}$ bis-GMA/aldehyde the comonomer ratios (mol\%) were G2: 72/26/2; G8: 69/23/8; G16: 63/21/16, and G24: 57/19/24. Resins were activated for visible light polymerization (LED Ultrablue IS, DMC Ltda, São Carlos, SP, Brazil; $350 \mathrm{~mW} . \mathrm{cm}^{-2}$ and $470 \pm 10 \mathrm{~nm}$ ) by the addition of CQ and DMPT (0.2 wt. (\%) each).

\subsection{Degree of conversion $(\% D C)$}

The $\%$ DC test was performed $(n=3)$ by means of a FTIR spectrophotometer (FTS 700-ATR, Varian Inc., Palo Alto, CA, USA) in transmission mode. Spectra were obtained in the region from 2000 to $1200 \mathrm{~cm}^{-1}$ and were acquired at a $4 \mathrm{~cm}^{-1}$ resolution and a total of 30 scans per spectrum. For comonomers, absorbance peaks were recorded by inserting the material into a Teflon disk-shaped mold (1 mm height $\times 5 \mathrm{~mm}$ diameter) adapted to a $\mathrm{NaCl}$ plate. A Mylar strip was used to press the unpolymerized material inside the mold in order to produce a very thin layer. The samples were then light polymerized for 40 seconds and the absorbance peaks of the copolymers were recorded. The percentage of monomer conversion was determined from the ratio of absorbance intensities of aliphatic $\mathrm{C}=\mathrm{C}$ (peak at $1637 \mathrm{~cm}^{-1}$ ) against the internal reference aromatic $\mathrm{C}=\mathrm{C}$ (peak at $1607 \mathrm{~cm}^{-1}$ ) peaks before and after the samples were polymerized. The $\% \mathrm{DC}$ was calculated $\mathrm{as}^{13}$ :

$\% \mathrm{DC}=\left[1-\left(\frac{\left(\operatorname{abs} \mathrm{C}=\mathrm{C}_{1637 \mathrm{~cm}^{-1}} / \mathrm{abs} \mathrm{C}=\mathrm{C}_{1607 \mathrm{~cm}^{-1}}\right) \text { polymerized }}{\left(\operatorname{abs} \mathrm{C}=\mathrm{C}_{1637 \mathrm{~cm}^{-1}} / \mathrm{abs} \mathrm{C}=\mathrm{C}_{1607 \mathrm{~cm}^{-1}}\right) \text { unpolymerized }}\right)\right] \times 100$ (1)

\subsection{Glass transition temperature $\left(T_{g}\right)$}

Comonomers and corresponding copolymers $\mathrm{T}_{g}$ were obtained using a differential scanning calorimeter (DSC 2010, TA Instruments, New Castle, DE, USA) each in duplicate, at heating rates of $20{ }^{\circ} \mathrm{C} / \mathrm{min}\left(1^{\text {st }}\right.$ run $)$ and $10{ }^{\circ} \mathrm{C} / \mathrm{min}\left(2^{\text {nd }}\right.$ run). For each experiment (comonomers or copolymers), about $15 \mathrm{mg}$ of resin per sample were proportioned, mixed, and in the case of copolymers, light activated (40 s irradiation; LED Ultrablue IS) prior to testing. In both tests, samples were scanned from -60 to $200{ }^{\circ} \mathrm{C}$ under a nitrogen atmosphere. The $\mathrm{T}_{g}$ was determined from the mid-point in the curve, as measured from the extensions of the pre- and post- transition baselines ${ }^{10,14}$.

\subsection{Rheological measurements}

Viscosity $(\eta)$ of the resins as a function of shear rate and the effect of temperature on complex viscosity $(\eta *)$ were performed by a dynamic oscillatory rheometer (AR1000-N rheometer, TA Instruments, New Castle, DE, USA) equipped with a stainless steel cone/plate geometry $\left(2^{\circ}\right.$ cone angle $/ 20 \mathrm{~mm}$ diameter; gap $0.69 \mu \mathrm{m}$ ) and strain amplitude set at $1 \%\left(25^{\circ} \mathrm{C}\right)$. Each comonomer was proportioned and mixed prior to testing. The frequency sweep test was completed over a range of $0.1-100 \mathrm{rad} / \mathrm{s}$. To evaluate the effect of temperature on $\eta^{*}$, measurements were taken as the temperature was increased from 25 to $40{ }^{\circ} \mathrm{C}$ at intervals of $1{ }^{\circ} \mathrm{C}$ at a frequency of $1.0 \mathrm{~Hz}$. Viscosity was measured at the shear rate of $5 \times 10^{-4}$ to $10 \mathrm{~s}^{-1}$ (shear stress of 0.05 to $500 \mathrm{~Pa})$ at $25^{\circ} \mathrm{C}$.

\subsection{Microhardness measurements $(H)$}

An $H$ tester (VMHT MOT, Leica Microsystems Wetzlar $\mathrm{GmbH}$, Germany) with Knoop diamond indenter was used under a $5 \mathrm{gf}$ load for 15 seconds. The test was performed for dry and wet disk-shaped ( $1 \mathrm{~mm}$ thick $\times 5 \mathrm{~mm}$ in diameter) specimens $(n=5)$. Wet specimens were tested after 7 days storage in deionized water $\left(37^{\circ} \mathrm{C}\right)$. The Knoop hardness number was determined by the arithmetic mean of five indentations randomly performed for each specimen and group. $H$ changes were obtained for each group by the percentage difference between baseline (dry) and final (wet) means ${ }^{11}$.

\subsection{Statistical analysis}

The $\% \mathrm{DC}$ and $H$ (dry, wet and \%change) data were analyzed by one-way ANOVA followed by Tukey-Kramer post hoc test. Differences between $H$ in dry and wet condition were analyzed by Student's t-test. Significance level was set at 0.05 .

\section{Results}

Mean \%DC values, $\mathrm{T}_{g}$ of comonomers and copolymers are given in Table 1. A gradual increase in \% DC from G0 to G24 was noted. G24 had a significantly higher degree of conversion than all other evaluated groups $(\mathrm{p}<0.001)$. The \%DC of G16 also differed statistically from G0 and $\mathrm{G} 2$. Inclusion of propionaldehyde in comonomers resulted in a reduction of $\mathrm{T}_{g}$ values as the mol\% additive increased. Conversely, no remarkable variation was seen in the copolymer $\mathrm{T}_{g} \mathrm{~s}$.

Figures $3^{g} \mathrm{a}-\mathrm{c}$ show representative rheological curves of the evaluated comonomers. All resins presented Newtonian behavior of viscosity (Figure 3a), which decreased linearly with increased temperature (Figure $3 b$ ). The $\eta^{*}$ decreased sigmoidally as the additive ratio increased (Figure 3c). G24 


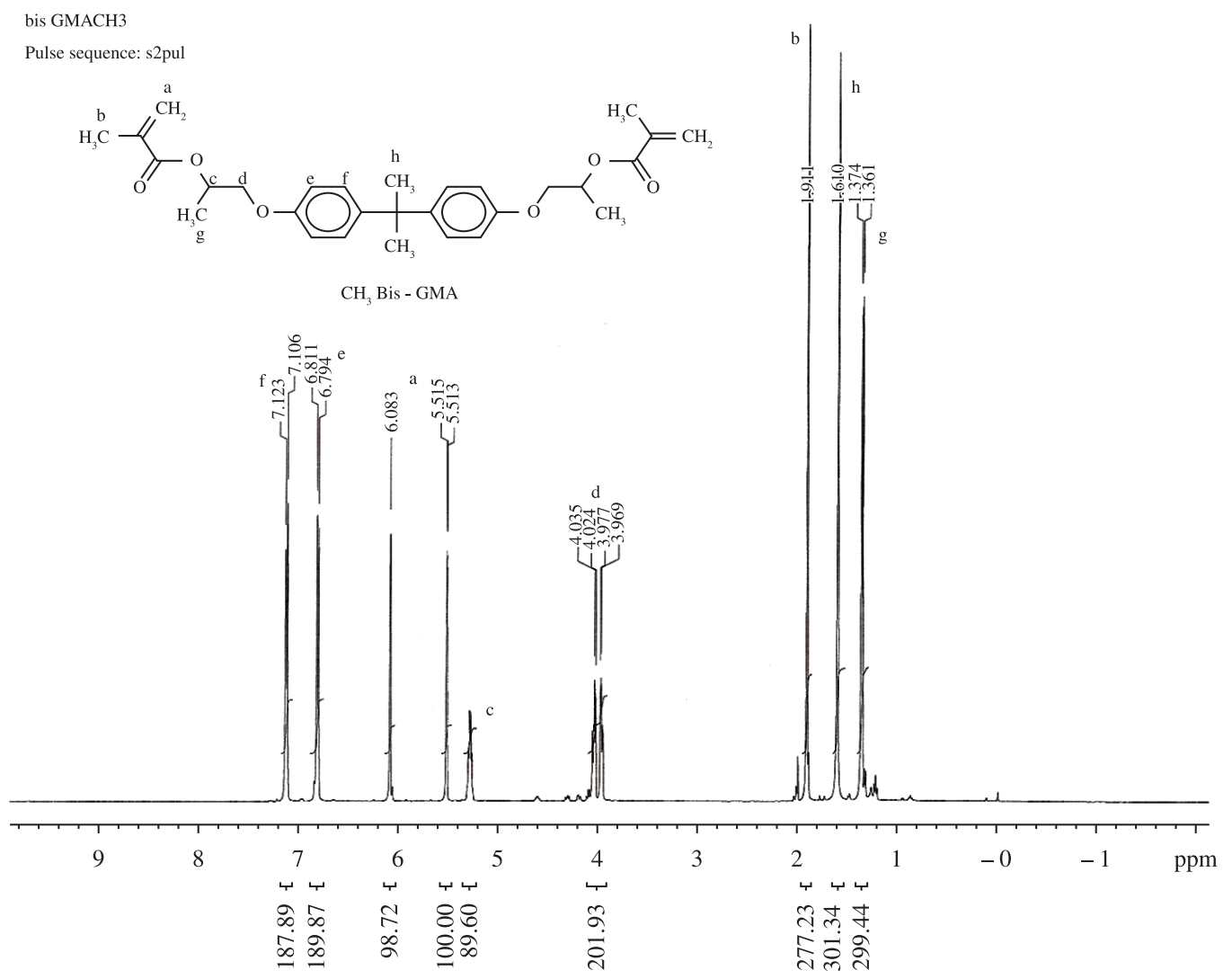

(a)

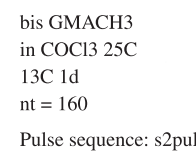

lse sequence: s2pul

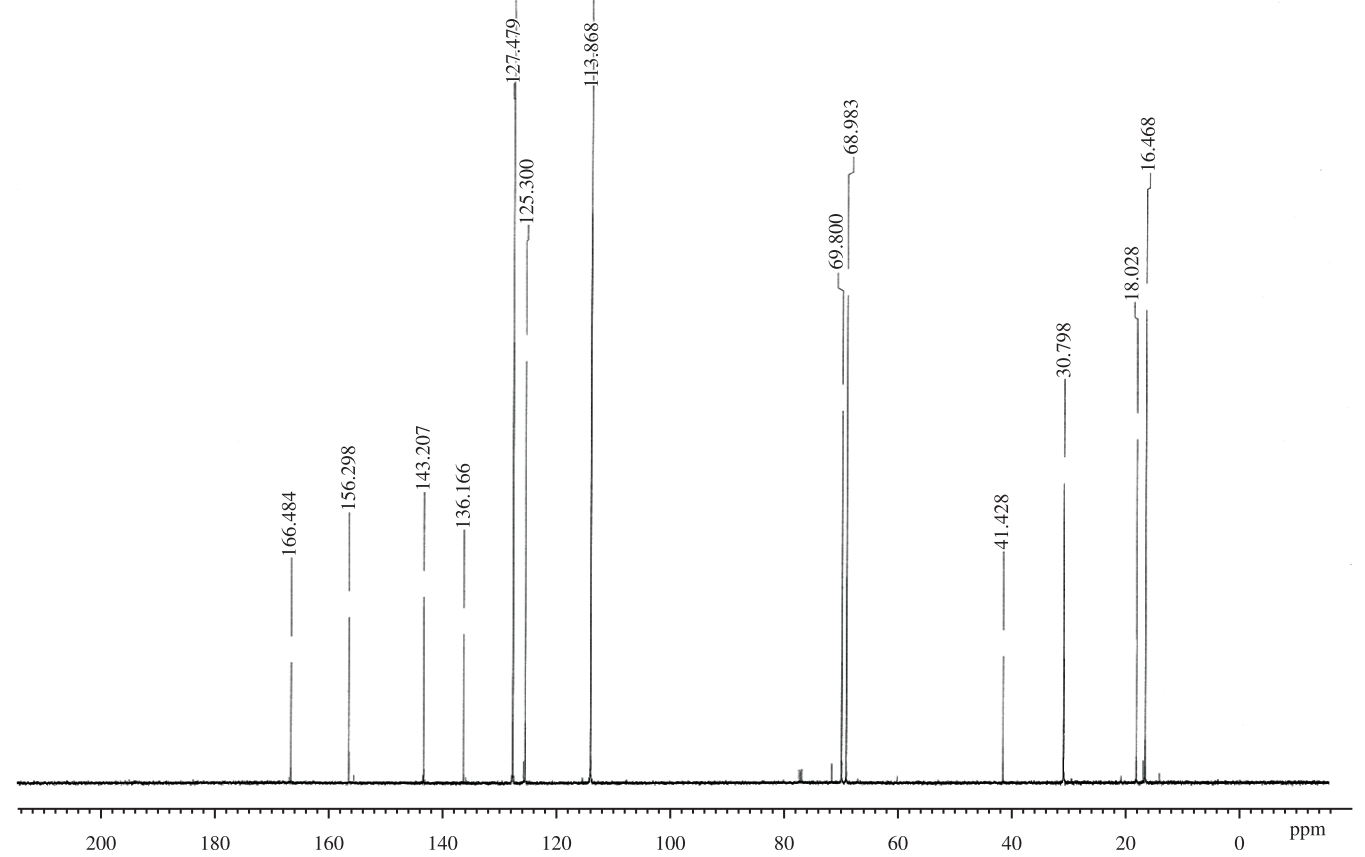

(b)

Figure 2. a) ${ }^{1} \mathrm{H}$ NMR spectrum of $\mathrm{CH}_{3}$ bis-GMA: the lower case letters correspond to the structures shown in the molecular structure; and b) ${ }^{13} \mathrm{C}$ NMR spectrum for $\mathrm{CH}_{3}$ bis-GMA. 
Table 1. Mean degree of conversion (\%DC), comonomer and copolymer $\mathrm{T}_{g}$ values.

\begin{tabular}{cccc}
\hline \multirow{2}{*}{ Groups } & \multirow{2}{*}{$\mathbf{D C}(\mathbf{s . d})$} & \multicolumn{2}{c}{$\mathbf{T}_{g}\left({ }^{\circ} \mathbf{C}\right)$} \\
\cline { 3 - 4 } & & Comonomers & Copolymers \\
\hline G0 & $38.0(2.6)^{\mathrm{a}}$ & -0.4 & 48 \\
G2 & $38.6(3.0)^{\mathrm{a}}$ & -5.4 & 48 \\
G8 & $40.0(1.7)^{\mathrm{a}, \mathrm{b}}$ & -5.4 & 49 \\
G16 & $44.3(1.5)^{\mathrm{b}}$ & -6.5 & 49 \\
G24 & $53.3(1.5)^{\mathrm{c}}$ & -7.0 & 50 \\
\hline
\end{tabular}

ANOVA and Tukey-Kramer, $\alpha=0.05$; s.d.: standard deviation; same letters indicate no statistical difference within same column.

had the lowest $\eta *$ (Table 2). Mean $H$ values are shown in Table 2. A gradual increase in $H$ values from G0 to G24 was also noted. G24 showed a significant difference ( $p<0.0001)$ when compared with the other groups for either dry or wet conditions. None of the groups had significant changes in $H$ from the dry to wet condition ( $\mathrm{p}>0.05)$. G0 had the highest $H$ change percentage $(\mathrm{p}<0.05)$, whereas G2 to G24 did not differ statistically from each other.

\section{Discussion}

The present findings revealed that the incorporation of propionaldehyde into the experimental resins gradually increased \%DC as the mol\% of the additive increased (Table 1). These results are in agreement with a previous study that reported increase in the conversion of comonomers based on bis-GMA/TEGDMA containing additive ${ }^{2}$, which was significant at higher ratios (24 to $32 \mathrm{~mol} \%$ ). With regard to the bis-GMA/CH $\mathrm{CH}_{3}$ bis-GMA system, G16 differed significantly from G0 and G2, and G24 differed from all groups. According to Peutzfeldt $(1997)^{15}$, propanal acts on resin conversion mainly by the chain transfer mechanism. The reaction would turn the transfer agents into free radicals. Due to their small size, they are able to react with double bonds in a growing polymer by hydrogen abstraction, which otherwise would not have reacted ${ }^{12}$.

Assessment of comonomer $\mathrm{T}_{g} \mathrm{~s}$ (Table 1) was considered important as it has been shown that aromatic methacrylates with low $\mathrm{T}_{g}$ and viscosity values exhibit higher degrees of conversion $^{16}$. With the addition of propanal, the bis-GMA/ $\mathrm{CH}_{3}$ bis-GMA system presented a decrease in comonomer $\mathrm{T} \mathrm{s}$ as the ratio of additive increased. Resins with lower $\mathrm{T}_{g}^{g} \mathrm{~s}$ also tend to reach vitrification at a higher extent of conversion ${ }^{10}$. For instance, among the evaluated groups, G24 exhibited the largest slot in $\mathrm{T}_{g}$ values between comonomer and copolymer $\left(-7\right.$ to $\left.50{ }^{\circ} \mathrm{C}\right)$ and the highest $\% \mathrm{DC}$ (53.3), followed by $\mathrm{G} 16\left(-6.5\right.$ to $\left.49{ }^{\circ} \mathrm{C} / \% \mathrm{DC}=44.3\right)$. On the other hand, copolymer $\mathrm{T}_{g} \mathrm{~s}$ were very similar, indicating that at ambient temperature, vitrification during polymerization of the samples tended to limit complete conversion ${ }^{14}$. It is also worth mentioning that since the reaction involved in this process is a free radical reaction, even at low conversion rates (i.e., group G0) the polymer attained a sufficiently high molecular mass in which the $\mathrm{T}_{g}$ value remained stable and independent of the \%DC.

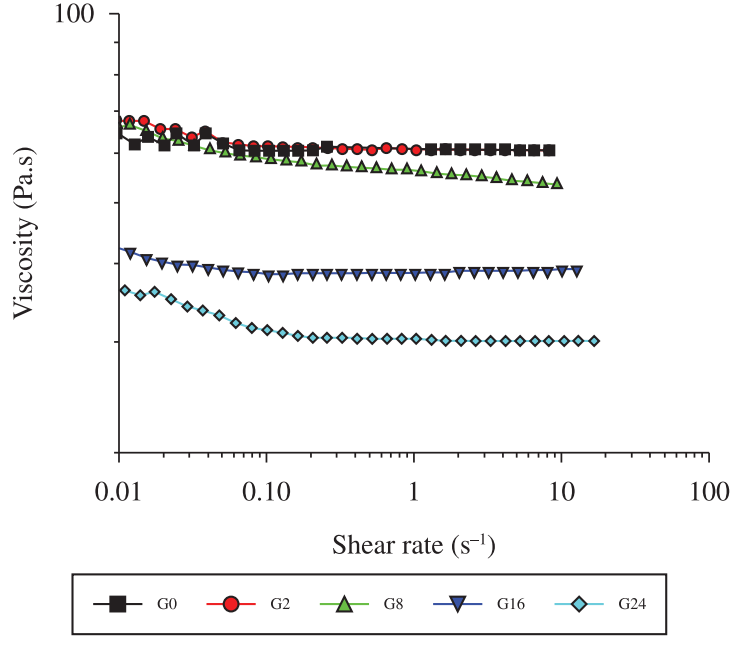

(a)

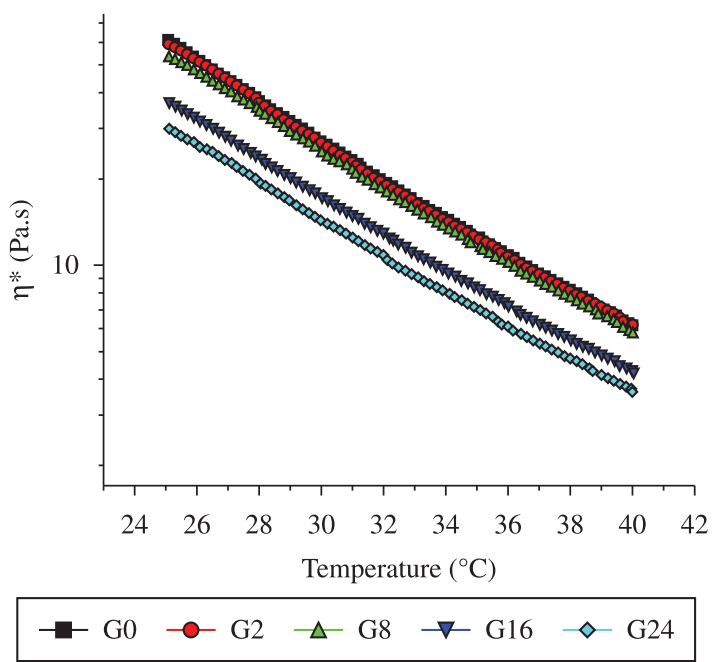

(b)

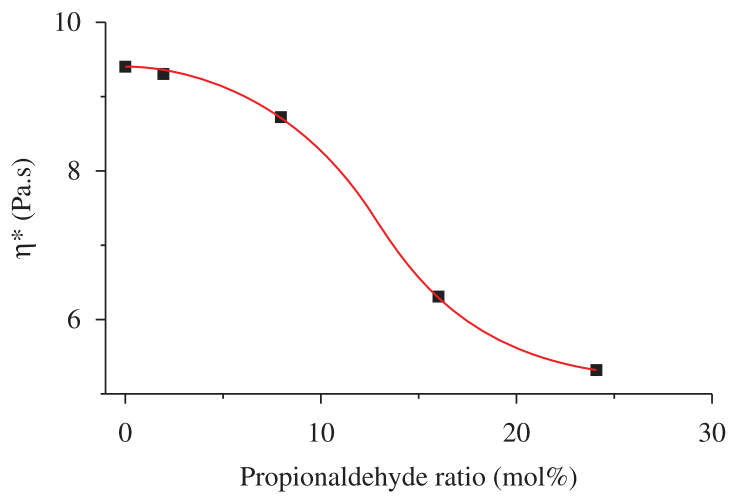

(c)

Figure 3. a) Viscosity as a function of shear rate; b) Complex viscosity as a function of temperature; and c) Complex viscosity as a function of $\mathrm{mol} \%$ propanal.

It has been reported that the viscosity of propionaldehyde is $3 \times 10^{-5} \mathrm{~Pa}$.s and its incorporation into comonomers significantly lowers the viscosity of $\mathrm{CH}_{3}$ bis-GMA-based resins ${ }^{10}$. Thus, alternatively to the chain transfer reactions, 
Table 2. Complex viscosity ( $\left.\eta^{*}\right)$, Knoop Hardness Number (KHN), and hardness change in experimental resins.

\begin{tabular}{ccccc}
\hline Groups & $\begin{array}{c}\eta^{*} \text { (Pa.s) } \\
\mathbf{3 7}^{\circ} \mathbf{C}\end{array}$ & $\begin{array}{c}\text { KNH (s.d.) } \\
\text { Dry }\end{array}$ & $\begin{array}{c}\text { KNH (s.d.) } \\
\text { Wet }\end{array}$ & $\begin{array}{c}\text { KNH (s.d.) } \\
\text { Change (\%) }\end{array}$ \\
\hline G0 & 9.41 & $13.3(1.2)^{\mathrm{Ad}}$ & $12.6(0.8)^{\mathrm{Af}}$ & $9.18(3.4)^{\mathrm{i}}$ \\
$\mathrm{G} 2$ & 9.28 & $14.0(0.7)^{\mathrm{Bd}}$ & $13.3(0.6)^{\mathrm{Bfg}}$ & $4.80(2.6)^{\mathrm{ij}}$ \\
$\mathrm{G} 8$ & 8.72 & $14.2(1.0)^{\mathrm{Cd}}$ & $14.0(0.7)^{\mathrm{Cg}}$ & $2.21(1.6)^{\mathrm{j}}$ \\
$\mathrm{G} 16$ & 6.31 & $14.6(0.6)^{\mathrm{Dd}}$ & $14.1(0.3)^{\mathrm{Dg}}$ & $3.86(2.7)^{\mathrm{j}}$ \\
$\mathrm{G} 24$ & 5.33 & $17.2(0.9)^{\mathrm{Ee}}$ & $16.5(0.8)^{\mathrm{Eh}}$ & $4.26(1.7)^{\mathrm{j}}$ \\
\hline
\end{tabular}

ANOVA and Tukey-Kramer, $\alpha=0.05$; s.d.: standard deviation; same lower case letters indicate no statistical difference within same column. Student's t-test, $\alpha=0.05$ : same upper case letters indicate no statistical difference within same line.

the sigmoidal decrease observed in comonomer viscosities (Table 2, Figure 3c) due to the presence of additive is likely to be the main contributory factor to their increased conversions. The sigmoidal curve describes phenomena in which very little change is apparent as a variable response ( 0 and 2 mol\% propanal), until a threshold that marks the onset of dramatic change is reached (from approximately 8 to $16 \mathrm{~mol} \%$ propanal) until a new stable state is reached. This reduced viscosity would delay the formation of crosslinked networks, thus increasing the collision and diffusion of newly formed free radicals. This enhanced mobility of reactive species also delays the auto-acceleration effect usually seen in bulk polymerization, facilitating more reaction between free radicals and double bonds, leading to increased conversion.

Moreover, all evaluated comonomers presented Newtonian behavior (Figure $3 a$ ) of $\eta$, i.e., relationship between the shear stress and strain rate was linear therefore the constant of proportionality = coefficient of viscosity. Differently from resin composites, which usually present pseudoplastic properties, the comonomer matrix usually displays Newtonian behavior in which their $\eta$ is independent of the shear rate ${ }^{17}$. With regard to composites, as the shear rate increases the comonomer molecules and inorganic particles undergo a change in the direction of alignment resulting in reduced interlocking between filler particles, and between filler particles and organic matrix, decreasing $\eta^{18}$. Figure $3 b$ shows that $\eta^{*}$ linearly decreased with the increase in temperature. This is expected to occur as the temperature rise provides the systems with higher activation energy, therefore increasing the agitation and motion of chain segments, and lowering the comonomer $\eta^{19}$.

\section{References}

1. Peutzfeldt A. Quantity of remaining double bonds of propanal-containing resins. Journal of Dental Research. 1994; 73(10):1657-1662. PMid:7929980.

2. Peutzfeldt A and Asmussen E. Effect of propanal and diacetyl on quantity of remaining double bonds of chemically cured BisGMA/TEGDMA resins. European Journal of Oral Sciences. 1996; 104(3):309-312. PMid:8831066. http://dx.doi. org/10.1111/j.1600-0722.1996.tb00082.x
An ongoing increase in $H$ values for dry and wet samples from G0 to G24, and a concomitant decrease in $H$ percentage change were observed (Table 2). There were no significant differences in $H$ values between dry and wet samples. In the wet condition, G24, G16 and G8 differed statistically from G0. In the dry condition, G24 differed significantly from baseline following the same trend as for \% DC in which G24 also presented the highest value and significance. Increased $\% \mathrm{DC}$ is known to improve resin mechanical properties such as surface hardness ${ }^{20}$. In the present study, group G24 indeed exhibited the significantly highest changes in the evaluated properties. However, G8 and specially G16 also exhibited differences for some properties (\%DC, $H$ wet, $H$ change) when compared with G0, falling within the range of the viscosity change curve. Therefore, future studies should assess the mechanical properties of G8 ( $8 \mathrm{~mol} \%$ propanal) and $\mathrm{G} 16$ (16 mol\% propanal) as well as the biocompatibility of these experimental resins.

\section{Conclusion}

Based on the foregoing experiments on the influence of different propanal ratios on bis-GMA/ $\mathrm{CH}_{3}$ bis-GMA experimental resins, the following conclusions were drawn:

- Incorporation of either 16 or 24 mol\% of propionaldehyde significantly increased comonomer degree of conversion;

- The group with 24 mol\% additive had the lowest comonomer $\mathrm{T}_{g}$, whereas no remarkable variation was noted in copolymer $\mathrm{T}_{g} \mathrm{~s}$;

- Increased propionaldehyde ratio led to lower comonomer viscosity values. All resins presented Newtonian behavior of viscosity, which linearly decreased with increased temperature;

- In the dry condition, the group with 24 mol\% additive had the highest microhardness value. In the wet condition, the groups with 8,16 , and $24 \mathrm{~mol} \%$ propionaldehyde had significantly increased microhardness values.

\section{Acknowledgements}

This study was supported by Conselho Nacional de Desenvolvimento Científico e Tecnológico - Brazil (Cnpq \# 133484/2005-0; ADB), Fundação de Amparo à Pesquisa do Estado de São Paulo - Brazil (Fapesp \# 2008/06170-7; RC), and by funds from the Faculty of Dentistry, University of Toronto - Canada (AP) and Connaught Start-up Award (AP).

3. Peutzfeldt A and Asmussen E. Influence of aldehydes on selected mechanical properties of resin composites. Journal of Dental Research. 1992; 71(8):1522-1524. PMid:1387138. http://dx.doi.org/10.1177/00220345920710081101

4. Peutzfeldt A and Asmussen E. In vitro wear, hardness, and conversion of diacetyl-containing and propanal-containing resin materials. Dental Materials. 1996; 12(2):103-108. http:// dx.doi.org/10.1016/S0109-5641(96)80076-5 
5. Braden M. The formulation of composite filling materials. Operative Dentistry. 1978; 3(3):97-102. PMid:296381.

6. Anseth KS, Newman SM and Bowman CN. Polymeric dental composites: Properties and reaction behavior of multimethacrylate dental restorations. Advances in Polymer Science. 1995; 122:177-217. http://dx.doi. org/10.1007/3540587888_16

7. Kalachandra S, Taylor DF, Deporter CD, Grubbs HJ and McGrath JE. Polymeric materials for composite matrices in biological environments. Polymer. 1993; 34(4):778-782. http:// dx.doi.org/10.1016/0032-3861(93)90363-F

8. Pereira SG, Nunes TG and Kalachandra S. Low viscosity dimethacrylate comonomer compositions [Bis-GMA and $\mathrm{CH}_{3}$ Bis-GMA] for novel dental composites; analysis of the network by stray-field MRI, solid state NMR and DSC \& FTIR. Biomaterials. 2002; 23(18):3799-3806. http://dx.doi. org/10.1016/S0142-9612(02)00094-7

9. Pereira SG, Osorio R, Toledano M and Nunes TG. Evaluation of two Bis-GMA analogues as potential monomer diluents to improve the mechanical properties of light polymerized composite resins. Dental Materials. 2005; 21(9):823830. PMid:15876451. http://dx.doi.org/10.1016/j. dental.2005.01.018

10. Prakki A, Tallury P, Mondelli RFL and Kalachandra S. Influence of additives on the properties of Bis-GMA/Bis-GMA analog comonomers and corresponding copolymers. Dental Materials. 2007; 23(10):1199-1204. PMid:17178149. http:// dx.doi.org/10.1016/j.dental.2006.10.007

11. Prakki A, Cilli R, Mondelli RFL and Kalachandra S. In vitro wear, surface roughness and hardness of propanalcontaining and diacetyl-containing novel composites and copolymers based on bis-GMA analogs. Dental Materials. 2008; 24(3):410-417. PMid:17688931. http://dx.doi. org/10.1016/j.dental.2007.06.011

12. Prakki A, Pereira PNR and Kalachandra S. Effect of propionaldehyde and 2,3-butanedione additives on the mechanical properties of Bis-GMA analog-based composites.
Dental Materials. 2009; 25(1):26-32. PMid:18757084. http:// dx.doi.org/10.1016/j.dental.2008.05.002

13. Atai M, Ahmadi M, Babanzadeh S and Watts D. Synthesis, characterization, shrinkage and curing kinetics of a new low-shrinkage urethane dimethacrylate monomer for dental applications. Dental Materials. 2007; 23(8):10301041. PMid:17493674. http://dx.doi.org/10.1016/j. dental.2007.03.004

14. Shankarpandian M, Shobha H K, Kalachandra S, McGrath JE and Taylor DF. Characterization of some aromatic dymethacrylates for dental composite applications. Journal of Materials Science Materials in Medicine. 1997; 8(8):465-468. PMid:15348711. http://dx.doi.org/10.1023/A:1018569908635

15. Peutzfeldt A. Retention of propanal and diacetyl in experimental resins. Acta Odontologica Scandinavica. 1997; 55:94-100. PMid:9176656. http://dx.doi.org/10.3109/00016359709115399

16. Shobha H K, Sankarapandian M, Schultz AR, McGrath JE, Kalachandra S and Taylor DF. Recent advances in free radical polymerization. Makromolekulare Chemie Macromolecular Symposia.1996; 111:73-83.

17. Lee IB, Min SH, Kim SY and Ferracane J. Slumping tendency and rheological properties of flowable composites. Dental Materials. 2010; 26(5):443-448. PMid:20170946. http://dx.doi. org/10.1016/j.dental.2010.01.003

18. Lee JH, Um CM and Lee IB. Rheological properties of resin composites according to variations in monomer and filler composition. Dental Materials. 2006; 22(6):515526. PMid:16171856. http://dx.doi.org/10.1016/j. dental.2005.05.008

19. Darvell BW. Materials Science for Dentistry. 4th ed. Hong Kong: BW Darvell; 2002.

20. Calheiros FC, Daronch M, Rueggeberg FA and Braga RR. Degree of conversion and mechanical properties of a BisGMA:TEGDMA composite as a function of the applied radiant exposure. Journal of Biomedical Materials Research Part B Applied Biomaterials. 2008; 84(2):503-509. PMid:17635039. http://dx.doi.org/10.1002/jbm.b.30897 